\title{
Microstructure and debris fracture in amorphous Ni-P-CNT composite coatings after wear
}

\author{
Bai Liu ${ }^{*}$, Xiaohong Yang \\ Shenzhem Institute of Information Technology, Shenzhen, 518172, P.R.CHINA \\ "Corresponding Author: e-mail: (Liu Bai) liub@sziit.edu.cn, co-author's e-mail: Yang Xiaohong (yangxh@ sziit.edu.cn)
}

\begin{abstract}
Amorphous nickel-phosphorus (Ni-P)-based Carbon Nanotubes (CNTs) composite coatings were prepared by brush electroplating technology. Wear tests for the coatings were conducted. The deformation of the microstructures in the coatings after wear was analyzed by transmission electron microscopy. The results showed that amorphous Ni-P-based composite coatings produced partial crystallization and precipitation of the $\mathrm{Ni}_{3} \mathrm{P}$ phase after wear. The degree of crystallization increased with the increase in load. Abrasive debris were collected for scanning electron microscope observation, which would help understand the microscopic mechanism of wear crack nucleation and propagation. The wear fracture of the debris in the amorphous Ni-P-based composite coating was intergranular and quasi-cleavage. The microscopic characteristics of the abrasive debris showed cutting stripes, secondary cracks, intensive areas of CNTs, and grain groups. The nucleation position of the wear crack was at the microstructure defects and grain boundaries; the wear crack propagation path was intergranular.
\end{abstract}

Keywords: CNTs, coating, nickel, wear, microstructures

DOI: http://dx.doi.org/10.4314/ijest.v8i3.1

\section{Introduction}

A material is expected to perform well against high temperatures to ensure good friction and wear properties under high friction condition. A layer of composite coating applied by electroplating provides hardness and heat-resistant characteristics to the surface of a material. This technique is an effective means to improve friction and wear properties. Carbon nanotubes (CNTs) that exhibit extremely strong mechanical characteristics and unique hollow structures are ideal materials for fabricating high-quality composites. Although composite coatings added to CNTs have been studied extensively (Tu et al., 2004; Tan et al., 2006; Li et al., 2006; Kim et al., 2009; Zarebidaki and Allahkaram, 2011), the role of CNTs in improving friction and wear properties remains unknown. Previous studies have reported that CNTs as reinforcement in coatings affect the micromechanism of the wear deformation and fracture. Complex stress and plastic deformation are observed on a worn surface and its layer during the friction and wear process (Suh, 1977; Rigney and Glaeser, 1978; Kuhlman-Wilsdorf, 1980; Zum, 1987; Bhushan et al., 1995).

In the process of sliding wear, no loss of material would occur when the interaction between the contact points is a completely reversible elastic deformation process. Wear is the process of plastic deformation and fracture of the surface and subsurface of materials, including the localized accumulation of plastic deformation; formation, expansion, and merger of wear and tear crack; and material separation. Abrasive debris is the product of wear fracture. Similar to a fracture, the surface of abrasive debris records large amounts of information of the wear fracture process. Thus, a study on abrasive debris helps understand the microscopic mechanism of wear. 


\section{Experiments}

\subsection{Compositions of brush electroplating bath}

The components of the brush electroplating solution are as follows: nickel sulfate $\left(\mathrm{NiSO}_{4} \cdot 7 \mathrm{H}_{2} \mathrm{O}\right), 200 \mathrm{~g} / \mathrm{L}$ to $250 \mathrm{~g} / \mathrm{L}$; nickel chloride $(\mathrm{NiCl}), 40 \mathrm{~g} / \mathrm{L}$ to $60 \mathrm{~g} / \mathrm{L}$; sodium hypophosphite $\left(\mathrm{NaH}_{2} \mathrm{PO}_{2} \cdot \mathrm{H}_{2} \mathrm{O}\right), 20 \mathrm{~g} / \mathrm{L}$ to $30 \mathrm{~g} / \mathrm{L}$; additives, $60 \mathrm{~g} / \mathrm{L}$ to $100 \mathrm{~g} / \mathrm{L}$; and suitable amounts of surfactants. The acidity-alkalinity $(\mathrm{pH})$ of the solution was 1.5 to 2.5 . Four groups of coating samples with different amounts of CNTs added in the plating solution were obtained, as shown in Table 1.

Table 1. Compositions of the composite coatings

\begin{tabular}{|c|c|c|}
\hline Coating & $\begin{array}{l}\text { Nickel - phosphorus } \\
\text { (Ni-P) plating solution }\end{array}$ & Added CNT (g/L) \\
\hline $\mathrm{Ni}-\mathrm{P}$ & $\checkmark$ & 1 \\
\hline $\mathrm{Ni}-\mathrm{P} / 0.5 \mathrm{~g}$ CNTs & $\checkmark$ & 0.5 \\
\hline $\mathrm{Ni}-\mathrm{P} / 1$ g CNTs & $\checkmark$ & 1.0 \\
\hline $\mathrm{Ni}-\mathrm{P} / 2 \mathrm{~g}$ CNTs & $\checkmark$ & 2.0 \\
\hline
\end{tabular}

\subsection{CNTs}

The CNTs were prepared by catalytic chemical vapor deposition (CCVD) (Liu et al., 2009). The CNT wall was clear, with few defects and impurities. Only a few amorphous carbons and graphite sheets were attached on the CNTs. The CNTs were long and slightly curved (as shown in Fig. 1), with a measured length longer than $700 \mathrm{~nm}$. The inner diameter of the CNT was approximately $5 \mathrm{~nm}$ to $20 \mathrm{~nm}$, and the outer diameter was approximately $20 \mathrm{~nm}$ to $40 \mathrm{~nm}$.

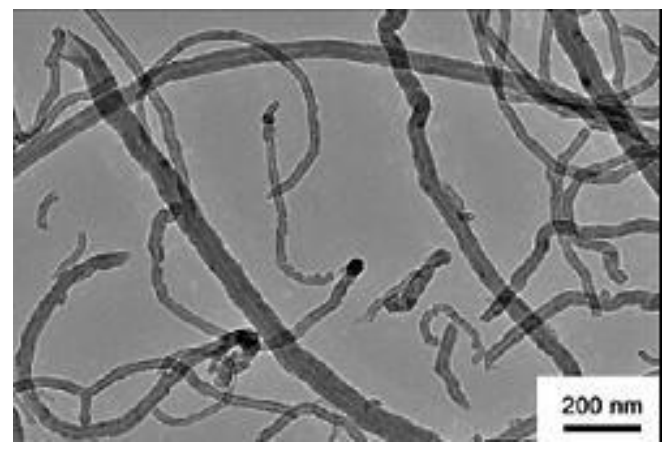

Figure 1. TEM image of CNTs prepared by CCVD

\subsection{Brush electroplating process}

After the CNTs with different weights were added into the plating solution using a 10,000 r/min electric mixer to agitate the solution for $5 \mathrm{~min}$, a uniformly dispersed and suspended compound bath was obtained. The pretreatment process of the samples was as follows: Electrocleaning (voltage: $+12 \mathrm{~V}$ ) $\rightarrow$ activation (voltage: $\pm 12 \mathrm{~V}$ ) $\rightarrow$ second activation (voltage: $\pm 18 \mathrm{~V}$ ) $\rightarrow$ nickel plating (voltage: $\pm 12 \mathrm{~V}$ ). Plating was carried out at temperature at room temperature, the current was 3 A to 6 A, the relative moving speed was $8 \mathrm{~m} / \mathrm{min}(0.13 \mathrm{~m} / \mathrm{s})$ to $12 \mathrm{~m} / \mathrm{min}(0.2 \mathrm{~m} / \mathrm{s})$, and the voltage was $12 \mathrm{~V}$. The Ni-P CNT coatings with different CNT content were made on a pin by the technique. The initial thickness of the Ni-P CNT composite coatings were about 0.6-08 $\mathrm{mm}$.

\subsection{Friction and wear tests}

The dry sliding friction coefficient and wear loss of the coatings were measured in the atmosphere with an M-200-type abrasion tester. The mount ring was quenched 45 steel $(0.45 \% \mathrm{C})$ with $53 \mathrm{HRC}$ hardness and $38.2 \mathrm{~mm}$ diameter. The test block was normalized 45 steel coated with the Ni-P-CNT Composites. The sample was immobile and the mount ring rotated at a speed of $0.4 \mathrm{~m} / \mathrm{s}$ for $3 \mathrm{~min}$. A 1 load of 100, 200, or $300 \mathrm{~N}$ was applied to the sample block through weights and leverage.

\subsection{TEM analysis}

A $0.5 \mathrm{~mm}$-thick sheet was cut from the coating parallel to the worn surfaces. The sheet was placed on a metal plate and ground into $50 \mu \mathrm{m}$ or less. Finally, a thin film was prepared as observation sample. The Hitachi 8100 transmission electron microscope with $200 \mathrm{kV}$, fourth beam spot, and $0.144 \mathrm{~nm}$ line resolution was used. The electron microscope was equipped with a Philips DK-4 energy-dispersive spectroscope, which can be used for chemical composition analysis. 


\subsection{Scanning electron microscope observation}

The abrasive Debris of coating was collected for surface morphology analysis. The Hitachi S-450-type scanning electron microscope (SEM) was used for this observation.

\section{Analysis of Microstructure}

The worn surface layer in the amorphous Ni-P matrix composite coating was observed by TEM. The results showed that the amorphous Ni-P matrix became slightly crystallized and precipitated a small amount of second phase particles. The electron diffraction analysis of the substrate confirmed that the Ni-P matrix remained amorphous (as shown in Fig. 2), which was evidently the result of the increase in temperature because of friction.
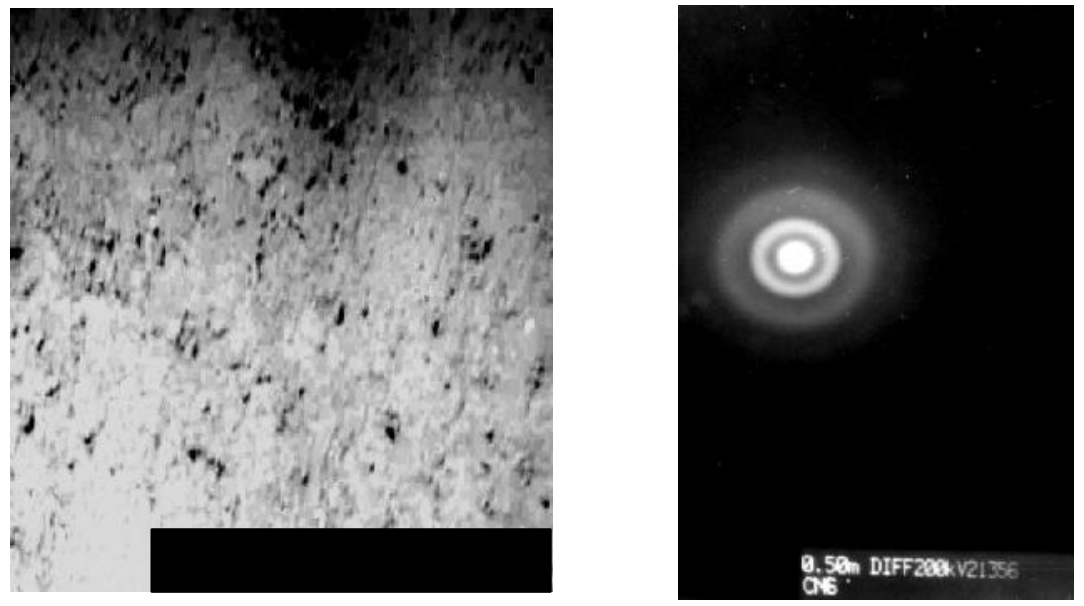

Figure 2. TEM image of the microstructure and electron diffraction pattern of the worn surface layer (amorphous Ni-P/2 g CNT, $150 \mathrm{~N}, 0.4 \mathrm{~m} / \mathrm{s}$ )

However, the local crystallization in the amorphous $\mathrm{Ni}-\mathrm{P}$ coating without carbon tubes was more severe at the same wear condition. Thus, more $\mathrm{Ni}_{3} \mathrm{P}$ phase particles precipitated from the substrate, as shown in Figure 3 .
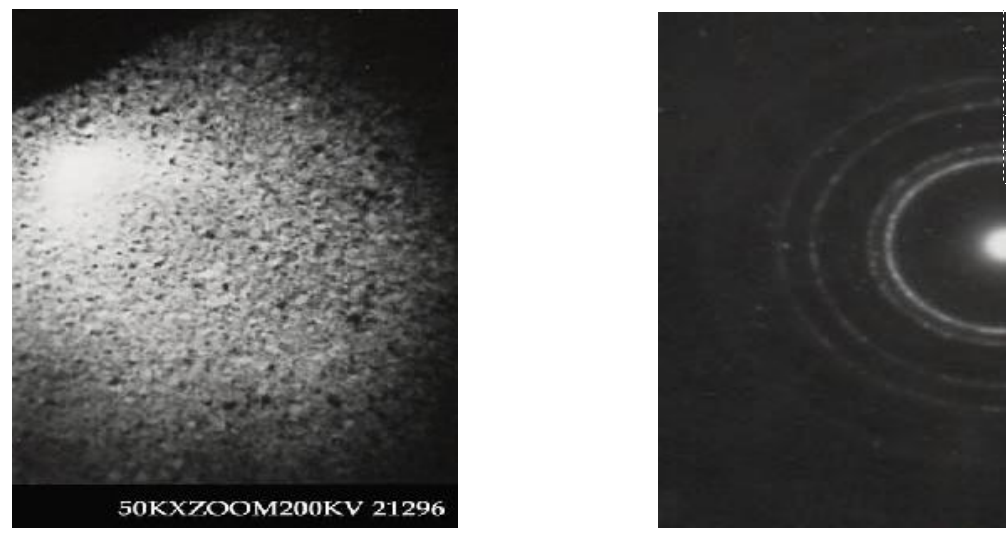

Figure 3. TEM image of the microstructure and electron diffraction pattern of the worn surface layer (amorphous Ni-P, $150 \mathrm{~N}, 0.4 \mathrm{~m} / \mathrm{s}$ )

Given that the hardness of the amorphous coating was not high, the wear mechanisms were mainly plowing and adhesion (Wang et al., 2012; Liu et al., 2013a). The plowing and adhesion mechanisms can cause the temperature at the contact area to increase rapidly. In Davim and Cardoso (2009), the average temperature of $120{ }^{\circ} \mathrm{C}$ and the maximum temperature of $680{ }^{\circ} \mathrm{C}$ at the contact area of the 45 steel friction pairs were obtained in the wear experiments of the ring block contact model with rough surface. For most microstructures, this temperature will cause the material to soften and exacerbate adhesion, thereby worsening the friction and wear. However, for the amorphous coating, especially the amorphous CNT composite coating, the temperature increase caused by friction leads to crystallizating (Liu et al., 2013b). Frictional heat was consumed. Crystallization induced the precipitation strengthening effect, which can suppress plowing and adhesion to a certain extent. This suppression of plowing and 
adhesion can be proven by the fact that, under heavy friction, the friction coefficient and wear loss for amorphous Ni-P carbon tube composite coating do not significantly increase (Bakshi et al., 2010; Liu et al., 2013c).

\section{Mechanism of the Wear Fracture}

The morphologies of the abrasive Debris from amorphous Ni-P-based composite coating are shown in Fig. 4, which reflect the microscopic characteristic and fracture mechanism of the coating in the wear process summarized in Table 2.
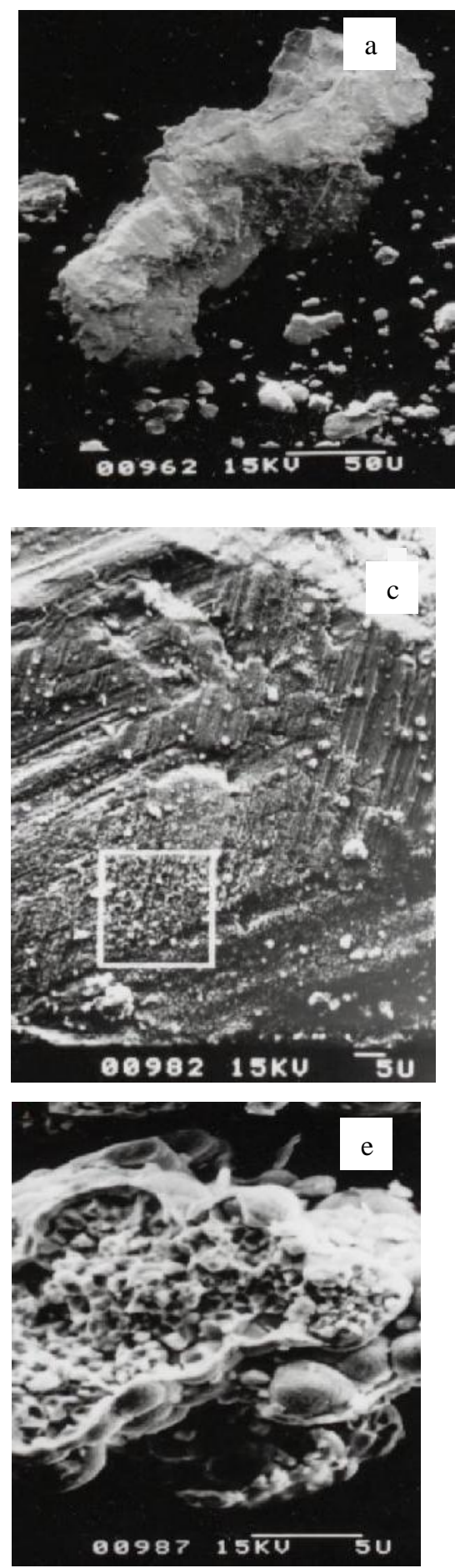
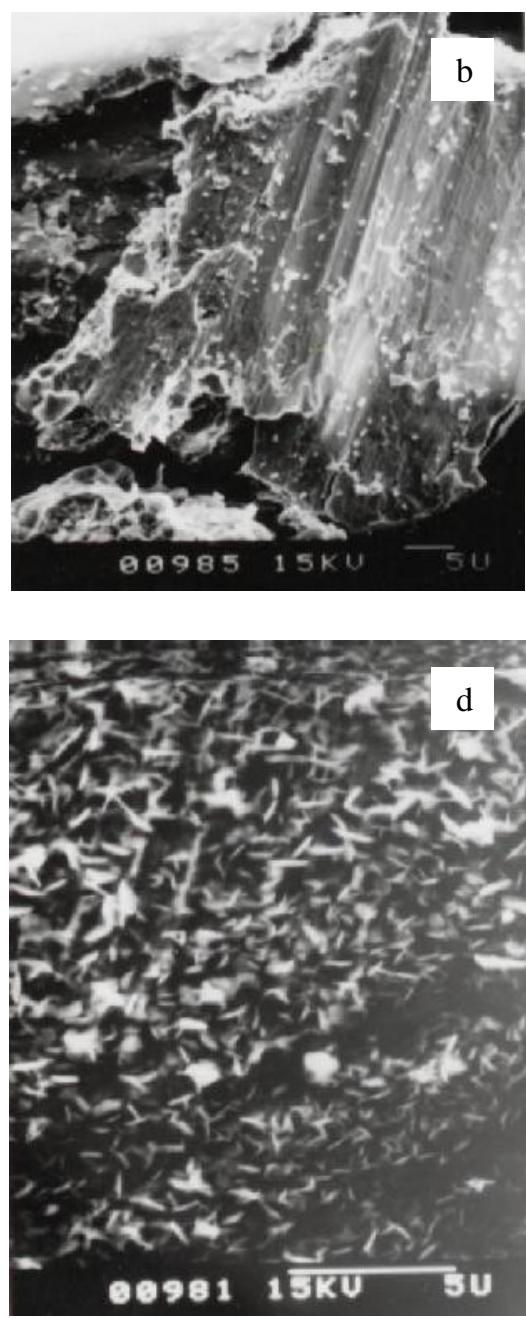

Figure 4. SEM images of abrasive Debris (amorphous Ni-P/1 g CNTs, 150 N, 0.4 m/s) (a, b. Bars, cake debris, and grinding marks; c, d .CNT densely populated areas and its enlarged view; e. grain group) 
Table 2. Wear fracture characteristics for the Debris of the coating in Figure 4

\begin{tabular}{ccccc}
\hline Coating type & $\begin{array}{c}\text { Microscopic } \\
\text { characteristics }\end{array}$ & Crack nucleation sites & $\begin{array}{c}\text { Crack propagation } \\
\text { paths }\end{array}$ & Facture natures \\
\hline Amorphous & Cutting stripes & Tissue defect & Quasi-cleavage & Grain boundaries \\
Ni-P based & and secondary & and grain & & \\
composite & cracks, intensive & boundaries & & \\
coating & areas of CNTS & & & \\
& and grain groups & & & \\
\hline
\end{tabular}

The coating material does not constitute typical brittle materials. However, the fracture of abrasive Debris is mainly characterized as a brittle fracture, which is a characteristic, as well as a disadvantage of wear fracture. The reason for this finding is related to the characteristics of friction and wear force, such as stress concentration and rapid dynamic, which cause severe plastic uneven damage and reduction of the response capacity of the material on load and embrittlement.

\section{Conclusion}

In the process of friction and wear, severe plastic deformation damages and structural changes occur at the worn surface. The amorphous Ni-P-based composite coatings produced partial crystallization and precipitation of the Ni3P phase. The degree of crystallization increased with the increase in load. The surface of abrasive debris records large amount of wear fracture information. Thus, the analysis of abrasive debris would help understand the microscopic mechanism of wear crack nucleation and propagation. Wear fracture of amorphous Ni-P-based composite coating is described as intergranular and quasicleavage. The microscopic characteristics of abrasive debris show cutting stripes, secondary cracks, intensive areas of CNTs, and grain groups. Wear crack nucleation is located at tissue defects and grain boundaries; the fracture path is along grain boundary.

\section{Acknowledgements}

We thank Science and Technology Plan of Shenzhen that gives us the financial support (grant no. JCYJ20140418100633644).

\section{References}

Bakshi S.R., Lahiri D., Agarwal A. 2010. Carbon nanotube reinforced metal matrix Composites - A review, International Materials Reviews, Vol. 55, No.1, pp. 41-64.

Bhushan B., Israelachvili J.N. and Landman U. 1995. Nanotribology: Friction, wear and lubrication at the atomic scale. Nature, Vol. 374, pp. 607-616.

Davim J.P., Cardoso R. 2009. Effect of the reinforcement (carbon or glass fibres) on friction and wear behaviour of the PEEK against steel surface at long dry sliding, Wear, Vol. 266, No. 7-8, pp. 795-799.

Kim IY, Lee JH, Lee GS, Baik SH, Kim YJ, Lee YZ. 2009. Friction and wear characteristics of the carbon nanotube-aluminum composites with different manufacturing conditions. Wear, Vol. 46, No. No. 2, pp. 86-91.

Li Z.H., X.Q. Wang, M. Wang, F.F. Wang, H.L. Ge. 2006. Preparation and tribological properties of the carbon nanotubes-Ni-P composite coating. Tribology International, Vol. 39, No. 9, pp. 953-995.

Liu B., Liu L., Liu X. 2013a. Effects of carbon nanotubes on hardness and internal stress in Ni-P coatings, Surface Engineering, Vol. 29, No. 7, pp. 507-510.

Liu B., Liu X., et al. Study on Synthesis process of carbon nanotubes by CCVD at lower temperature. 5th International Conference on MEMS Nano, and Smart Systems (ICMENS 2009), pp. 122-124.

Liu B., L. R. Liu, X. J. Liu. 2013b. Effects of carbon nanotubes on crystallization in amorphous Ni-P electroplating coating. Surface Engineering, Vol. 29, No. 3, pp. 190-193.

Liu X., Liu B. 2013c, Effect of carbon tube on friction and wear properties of Ni-P coating, Hot Working Technology, Vol. 42, No.14, pp.115-119.

Rigney D.A., Glaeser W.A. 1978. The significance of near surface microstructure in the wear process. Wear, Vol. 46, No. 1, pp. 241-250.

Suh N. P. 1977. An overview of the delamination theory of wear. Wear, Vol. 44, No. 1, pp. 1-16.

Kuhlman-Wilsdorf D. 1980. Fundamentals of friction and wear of materials. Metals Park, Ohio, American Society of Metallurgy, p. 123.

Tan J., Yu T., Xu B., Yao Q. 2006. Microstructure and wear resistance of nickel-carbon nanotube composite coating from brush plating technique, Tribology Letters, Vol. 21, No. 2, pp. 107-111. 
Tu J P , Zhu L P, Chen W X. et al. 2004. Preparation of Ni- CN T composite coatings on aluminum substrate and its friction and wear behavior, Transactions of Nonferrous Metals Society of China, Vol.14, No. 5, pp. 880-884.

Wang J., Yan F., Xue Q. 2009. Friction and wear behavior of ultra-high molecular weight polyethylene sliding against GCr15 steel and electroless Ni-P alloy coating under the lubrication of seawater, Tribology Letters, Vol. 35, No. 2, pp. 85-95

Zarebidaki A., Allahkaram S.R. 2011. Effect of surfactant on the fabrication and characterization of Ni-P-CNT composite coatings, Journal of Alloys and Compounds, Vol. 57, No. 7, pp. 156-160.

Zum G. K H. Microstructure and Wear of Materials. Amsterdam: Elsevier,1987:76.

\section{Biographical notes}

Liu Bai is from Shenzhem Institute of Information Technology, Shenzhen, 518172, P.R.CHINA

Yang Xiaohong is from Shenzhem Institute of Information Technology, Shenzhen, 518172, P.R.CHINA

Received April 2016

Accepted April 2016

Final acceptance in revised form June 2016 